\title{
Preventive care for burnout: General practitioner pilot program in Barcelona
}

\author{
Jorge L. Tizón ${ }^{1,2^{*}}$, Pau Gràcia ${ }^{2}$, Anna Larripa $^{2}$, Jordi Artigue ${ }^{1,2}$, Josep Casajuana ${ }^{2}$ \\ ${ }^{1}$ Mental Health Prevention and Early Attention Team for Patients at Risk for Psychosis (EAPPP), Catalan Health Institute (Institut \\ Catalá de la Salut), Barcelona, Spain; 'Corresponding Author: jtizong@gmail.com \\ ${ }^{2}$ Primary Care, Catalan Health Institute (Institut Catalá de la Salut), Barcelona, Spain
}

Received 21 February 2013; revised 21 March 2013; accepted 10 April 2013

Copyright @ 2013 Jorge L. Tizón et al. This is an open access article distributed under the Creative Commons Attribution License, which permits unrestricted use, distribution, and reproduction in any medium, provided the original work is properly cited.

\section{ABSTRACT}

Background: Despite the prevalence of "professsional exhaustion syndrome" or "burnout", very few intervention programs for healthcare professionals have been proposed, and even fewer have been evaluated. The Catalan Health Institute requested an intervention that would be preventive, integrated, and would differentiate between those affected by burnout and those with established psychopathologic disorders requiring specific treatment. Aims: To describe the experience and initial reflections from the first cohort of primary care physicians in the Barcelona public health system to participate in a program designed to prevent burnout. Methods: Descriptive analysis of the characteristics of this secondary prevention program: design, cost estimates, recruitment and screening, and activities (training, organization, and group techniques). Particular emphasis on the process of identifying potentially affected professionals, how they were offered the opportunity to participate, and the coordinated and confidential nature of the program. Results: Of a target population of 969 family doctors and pediatricians in public primary care services in Barcelona, $6(0.61 \%)$ applied for full program participation. All of them, along with 2 non-medical professionals in primary care services who joined the program, met the clinical and psychometric criteria (Shirom-Melamed Burnout Measure, General Health Questionnaire, and the 16 Personality Factors Questionnaire) of the desired participant profile. Conclusions: The level of participation could suggest defects in program design or, alternatively, problems in the concept of burnout. This construct may be more useful for detecting stress attributed to occupational contexts than for facilitating participation in activities related to its prevention or treatment.

Keywords: Burnout; Psychopathology; Preventive Programs; Professional health; Mental Health

\section{INTRODUCTION}

The use of the metaphorical term of "burnout" has suffered from problems of conceptual boundaries since its introduction by Freudenberger [1], Maslach and Jackson [2]. Attempts to alleviate these problems have proposed diverse alternatives: "professional exhaustion syndrome", "job burnout", "work stress" or "professional disillusionment syndrome" are just a few of the more or less synonymous terms applied to a situation that everybody talks about but that is still far from being sufficiently defined.

First, we must establish that this is a psychosocial rather than a medical syndrome. Freundenberger [1] observed and described the phenomenon as "a state of fatigue or frustration that is produced by dedication to a cause, lifestyle or relationship that does not produce the anticipated support”. Shirom [3], applying the Conservation of Resources (COR) theory, defines burnout as an affective state characterized by feelings of insufficient physical, emotional and cognitive energy: burnout tends to occur when an individual experiences actual or threatened loss of internal or external resources and lacks the resources needed to compensate for that loss.

Various instruments have been proposed to measure this syndrome, each of them with multiple adaptations and versions, but in addition to inherent psychometric challenges they all have problems with construct validity, external validity and comparability, as a consequence of fundamental conceptual issues [4]. In healthcare, the most common instruments are the Maslach Burnout In- 
ventory (MBI) [2], its Spanish version, the CESQT; and the Shirom-Melamed Burnout Measure (SMBM) [5,6]. Despite the differences between them, these three research groups agree on a series of theoretical elements: 1) Burnout syndrome is far from conclusively defined. 2) The internal reliability of the construct is questionable. 3) Instruments intended to measure burnout have similar problems. 4) Therefore, the internal dimensions of the construct and of the associated measurement instruments vary widely.

Given these considerations, it is difficult to make prudent generalizations. Some studies have reported that up to $30 \%$ of doctors are "burned out"; rates vary by study design and healthcare professionals studied, ranging from $3.25 \%$ to $30 \%$ [4,7-10]. Generally, rates are higher for nurses, particularly in psychiatric nursing [10,11].

Studies have also been done on other occupations: personal care attendants, teachers, fire and police forces [4,12-14]. Overall, a review of literature from 1990 through 2002 by Boudreau and Nakashima [14] identified 2138 publications on the topic and Shirom [3], in a more recent review using Google Scholar, found more than 260,000 entries using the search term "burnout". In our own January 2013 search, we found 432,000 entries: 318,000 for "burnout" and 114,000 for "burn-out" (339,000,000 using the standard Google search engine).

Individuals who have experienced burnout or a loss of resources tend to change their health habits; this coincides with the important, and pioneering research on psychosomatic aspects of occupational stress and social inequality [15]. Furthermore, Ahola et al. [16] found that burnout is predictive of disease-related disability in Finland, where $22 \%$ of those who received a disability pension in that country in 2000 suffered from severe burnout syndrome according to their MBI scores.

Is burnout a mental disorder or not? Can it be assimilated into one of those proposed in the literature? Or is it a different construct for a different context, perhaps psychosocial? One of the elements that could give the construct better coherence would be to differentiate it from more generalized and accepted types of "mental disturbance” (for instance, in the International Classification of Diseases [ICD-10], or American Psychiatric Association Diagnostic and Statistical Manual [DSM-IV]). In any case, it is especially relevant to take into account the psychopathology of health professionals. Recently the "Caring for caregivers" working group of the Catalan Government's Directive on Mental Health and Addictions (Pla Director de Salut Mental i Adiccions de la Generalitat de Catalunya 2006-2010) and the team for "Professional Health" collected data on this topic [17], which we have summarized in Table 1.

Nonetheless, there is no doubt that, whether or not it begins as a mental disorder and specifically as a typical
Table 1. Estimated prevalence of psychopathology in healthcare professionals and in general population.

\begin{tabular}{ccc}
\hline Psychopathology & General population & Physicians \\
\hline Mental disorders & $15 \%-20 \%$ & $28 \%$ \\
Depression & $5 \%$ & $10 \%$ \\
Suicide & $6-9 / 100,000$ & $15 / 100,000$ \\
Substance abuse & $5 \%$ & $15 \%$ \\
Self medication & $?$ & $5 \%$ addicts \\
\hline
\end{tabular}

Derived from the references cited [17,20,25], particularly Generalitat de Catalunya [17].

adjustment disorder, chronic burnout syndrome is a risk factor for the development of well-defined mental disorders that can be diagnosed: primarily anxiety, somatoform, depression and personality disorders [17-21].

Finally, our experience as we work with organizations suggests the following: First, it may be impossible for any organization to sustain itself if $30 \%$ of its personnel suffer from chronic burnout syndrome. Second, in epidemiological studies, the tendency for "external attribution" or the "projection" of personal discomfort to the organization may facilitate self-identification as being "burned out".

\section{METHODS}

Despite the likelihood of broad prevalence of the syndrome, very few intervention programmes for healthcare professionals have been proposed, and even fewer have been evaluated [19-25]. The objective of this project was to develop a multidimensional action specifically directed at healthcare professionals in family medicine who experience burnout, and to evaluate the results.

At the time of the study, the City of Barcelona had a population of 1,619,337 and 969 primary care physicians in the healthcare system (1671:1). The Barcelona primary care services of the Catalan Health Institute (Institut Català de la Salut, ICS) requested collaboration in designing a programme on burnout from the Occupational Health and Safety Unit (USL) and the ICS team working on the prevention of mental disorders (EAPPP). During 2009, a working group collaboratively designed a preventive intervention process called APEP (Ajuda Preventiva en l'Esgotament Profesional), or "Helping to Prevent Professional Exhaustion”, oriented towards secondary prevention of the syndrome. They took into account not only the prior experience of members of both preventive groups, but also some existing studies of similar interventions [16,20-31].

The proposed intervention was intended to have the following characteristics:

1) Preventive, rather than addressing well-established burnout syndromes. 
2) Integrated, taking into account, both in prevention and treatment, the methods and techniques about which international experts agree (groups, group learning activities to improve knowledge, skills and abilities [KSAs], organizational abilities and psychotherapy systems rooted in counselling strategies).

3) Differentiation between those professionals affected by "professional exhaustion syndrome" or "burnout" and those with established psychopathologic disorders who, even if they meet the criteria for inclusion, instead require specific treatment for an existing disorder. In order to achieve this differentiation, we used psychometric tools and additional psychiatric interviews. Two psychiatrists with a combined total of 71 years of experience assisted in differentiating between these two profiles.

Table 2 shows the structure of the full APEP programme and its four basic sections. The first programme offering was designed and implemented in 2011, before the 2010 political and economic crisis swept through European public health systems.

We consider the evaluation of this first effort an essential step toward the second attempt, with an alternate format, and the eventual comparative analysis of the two approaches. The total cost of the first APEP was 17,000 Euros. The second model will use a shorter two-step protocol: initial psychopathology assessment and brief, focused psychotherapy.

Primary care doctors received information about registering for the APEP programme in four ways:

1) Two personalized email announcements from the APEP team to the entire group, with a certification of receipt.

2) Direct presentations to all healthcare centre directors in Barcelona.

3) Direct presentations by the programme coordinators in specific healthcare centres, used as pilot centres for dissemination.

4) Offers of self-assessment of "professional exhaustion" or "burnout" by taking the Shirom-Melamed Burnout Measure (SMBM), posted prominently on the homepage of the Barcelona City Primary Care website.

Target population: 969 Barcelona primary care doctors.

Inclusion criteria: 1) Family doctors engaged in direct clinical care; in the end, because of the number of places available (20) and their expressed interest, one nurse and one social worker working in the primary health system were also included. 2) Self-identified or recommended by colleagues or supervisors as either "burned out" or at risk. All participants provided signed informed consent.

Exclusion criteria: 1) Obvious or diagnosed psychopathology already known to the Occupational Health and Safety Unit. 2) Very advanced, long-term or chronic process of professional burnout. 3) Evidence of serious psychopathology in the exploratory interviews.

Exclusion criteria were assessed during the applicant's individual interviews with the team's two psychiatrists. Before the second interview, each applicant completed a variety of psychometric tests used in the APEP programme. A third interview was an option if necessary.

Objective of the interviews: To characterize each applicant profile into one of three possible categories:

1) No evidence of professional exhaustion syndrome (not an APEP profile), nor evidence of psychopathology.

2) Signs of professional burnout or exhaustion syndrome, and could benefit from APEP participation.

3) Needs specialized assistance, whether psychiatrist or psychotherapist (the third interview could be used to discuss this need with the individual).

To evaluate the programme, we chose four criteria: Written evaluation by participants for each of the four sections, evaluation in discussion groups, psychometric assessment and overall evaluation of the APEP team. For the psychometric evaluation we used the Castilian Spanish or Catalan version of the SMBM [6], the GHQ-28 and 16-Personality Factors. Table 2 summarizes the programme activities and their duration.

Ethics Committee approval: The study about this pilot project was approved by the Ethics Committee for Clinical Research of the IDIAP Jordi Gol.

\section{RESULTS}

Of the 969 doctors (818 family doctors and 151 paediatricians) in the City of Barcelona's primary care system, 11 health professionals (including 9 physicians, a nurse and a social worker) expressed interest in the programme, but only 8 participated in the interview phase. Finally, 6 general practitioners $(0.61 \%)$ requested participation in the programme. All of the interested individuals met the inclusion criteria. Participant characteristics are shown in Table 3. Participants' written evaluations and comments from the four who attended the final evaluation meeting were unanimously positive (in two cases, highly positive) about the programme and their appreciation for the opportunity to participate.

The clinical APEP team's own final assessment was somewhat different. We felt that two of the participants who completed the programme had benefited greatly, one was ambivalent about the results, and another vacillated between ambivalence and a feeling that nothing had changed. Of the four whose attendance was interrupted, our evaluation was positive in one case and we had no information about the other three participants.

\section{DISCUSSION}

When we started this programme, we were surprised at first. According to our research and to informal conver- 
Table 2. APEP programme activities (66.5 hours).

\begin{tabular}{|c|c|c|c|}
\hline $\begin{array}{l}\text { Group orientation } \\
\text { Two } 2.5 \text {-hour sessions }\end{array}$ & $\begin{array}{c}\text { Training in } \\
\text { specific areas } \\
\text { Seven 3-hour sessions }\end{array}$ & $\begin{array}{l}\text { Group experiences } \\
\text { Seven 2.5-hour sessions } \\
\text { following each training } \\
\text { session in Specific Areas }\end{array}$ & $\begin{array}{c}\text { Balint-style group } \\
15 \text { bi-weekly } \\
\text { 1.5-hour sessions }\end{array}$ \\
\hline $\begin{array}{l}\text { Technique: "group dynamics } \\
\text { with prior stimulus" } \\
\text { Topics: Professional exhaustion } \\
\text { and psychopathology } \\
\text { Psychological components of } \\
\text { medical practice } \\
\text { Introduction to APEP }\end{array}$ & $\begin{array}{l}\text { 1) How to manage medical consultation } \\
\text { 2) The hyper-frequent patient } \\
\text { 3) Time management during appointments } \\
\text { 4) The "sacred" consultation: Vital, daily, primary care } \\
\text { consultations } \\
\text { 5) Legal standards of interest to the Family Doctors. } \\
\text { Responding to an attack } \\
\text { 6) Ethics and conflict resolution } \\
\text { 7) Useful psychological techniques for Primary Care }\end{array}$ & $\begin{array}{l}\text { Group oriented toward } \\
\text { experiences and attitudes } \\
\text { within organizations. }\end{array}$ & $\begin{array}{l}\text { Focal group oriented to } \\
\text { reflection about the } \\
\text { psychological problems of } \\
\text { professionals; specific patient } \\
\text { cases are proposed each } \\
\text { session by the participants }\end{array}$ \\
\hline 5 hours & 21 hours & 18 hours & 22.5 hours \\
\hline
\end{tabular}

sations in our primary care centres, clinical and scientific sessions, and confidences shared by medical professionals in moments of spontaneity and relaxation, burnout exists and is frequent in our healthcare system. Nonetheless, despite the four systems put into place to offer preventive support through the APEP programme, the number of full applications was abnormally few: 6 doctors, just $0.61 \%$ of the eligible population, a highly significant difference from any of the participation rates we could have anticipated from "epidemiological" studies (ranging from $3.25 \%$ to $30 \%$, according to other epidemiological studies in our country and others) $[4,14,24-33]$.

We must here limit ourselves, then, to merely descriptive data that will need to be reassessed in light of future cohorts and larger participant groups (Table 3).

Our psychometric data points to the appropriate psychometric characteristics of the SMBM [5], which is the reason we chose this test. They also point out the difficulty of detecting changes in this small study group with SMBM. The GHQ seems more sensitive to changes in this small cohort.

All of the participants received a DSM-IV diagnosis from the collaborating psychiatrists who evaluated them (which does not in any way indicate that they were unable to perform their professional duties). The predominant diagnoses were "narcissistic personality disorder" and "major depression", along with "adjustment disorder". Both our clinical impression and the results of administering the GHQ and 16PF questionnaire led us to describe most of the participants as extremely sensitive, dutiful, self-critical—sometimes even perfectionist—and with high rates of anxiety and tension, who had to rely heavily on self-control with the inherent possibility of finding themselves without the resources needed to indefinitely sustain those qualities.

The $0.61 \%$ rate of programme registration required that we redesign the programme or, on a broader level, rethink the epidemiology and the research literature on burnout or "professional exhaustion syndrome" [30,31, 34-37]. The usual data show that when doctors assess their own burnout, the rates of "positive" responses, both to direct questions and on the various tests that specifically identify the syndrome, are very high. However, when we offered the possibility of participating in a comprehensive, evidence-based, capacity-building programme of burnout prevention, with strict guarantees of confidentiality, etc., many fewer respondents identified by SMBM or self-identified as "burned out" applied for an appropriate assistance programme.

This contradiction must cause us to reflect, not only about our own programme and its publicity and recruitment methods, but also about the concept or notion of burnout and "professional exhaustion syndrome" and the processes, results and significance of self-assessment by healthcare professionals. Our APEP team came up with several possible explanations: 1) Dissemination of APEP information might have been poorly designed and therefore did not inspire participation. 2) The syndrome, as well as the instruments by which it is assessed, is not well defined from a theoretical and clinical perspective and therefore yields paradoxical and controversial results, especially an excess of "false positives". We cannot dismiss these arguments because, as we have seen, the notion of burnout possesses dubious construct validity. 3) It is impossible to distinguish between burnout and psychopathology, at least with the procedures usually utilized. This is supported by the GHQ findings. Does this mean that all professionals with psychopathology profiles such as those shown in Table $\mathbf{3}$ should participate in APEP? This would require "treating" more than 200 professionals in our context, which is impossible and probably improper from an ethical and healthcare perspective. 4) Perhaps the notion of burnout or professional exhaustion syndrome and its extensive use in university and healthcare environments, as we have noted previously $[4,14,35,36]$, over encourages both external projection (attribution to external causes) and loss of the capacity for self-perception.

The psychopathology perspective in mental health research has developed over more than two centuries, so it 
Table 3. Summary of APEP participant characteristics, $1^{\text {st }}$ cohort.

\begin{tabular}{|c|c|c|c|c|c|c|c|c|}
\hline \multicolumn{4}{|c|}{ Evaluation: Baseline } & \multicolumn{3}{|c|}{ Re-evaluation (control) } & \multirow[b]{2}{*}{$\begin{array}{l}\text { Probable } \\
\text { DSM-IV } \\
\text { Diagnosis }\end{array}$} & \multirow[b]{2}{*}{$\begin{array}{c}\text { Clinical Evaluation } \\
\text { of Programme } \\
\text { Results }\end{array}$} \\
\hline Key & $\begin{array}{c}\text { SMBM }^{*} \\
\text { (Shirom-Melamed } \\
\text { Burnout Measure) }\end{array}$ & $\begin{array}{c}\text { GHQ } \\
\text { (General Health } \\
\text { Questionnaire) }\end{array}$ & $\begin{array}{c}16 \mathrm{PF}^{* *} \\
\text { (16-Personality Factors } \\
\text { Questionnaire) }\end{array}$ & $\begin{array}{l}\text { S } \\
\text { M } \\
\mathbf{B} \\
\mathbf{M}\end{array}$ & GHQ & $16 \mathrm{PF}$ & & \\
\hline 1 & $60+$ & 5 & $\begin{array}{c}\text { Warmth } 3 \\
\text { Emotional Stability } 3 \\
\text { Rule Consciousness } 3 \\
\text { Social Boldness } 3 \\
\text { Abstractedness } 8 \\
\text { Self-reliance } 10 \\
\text { Perfectionism } 8 \\
\text { Anxiety } 8\end{array}$ & & & & NPD & $+?$ \\
\hline 2 & $21+$ & 0 & $\begin{array}{c}\text { Dominance } 8 \\
\text { Social Boldness } 8 \\
\text { Sensitivity } 8 \\
\text { Openness to change } 9 \\
\text { Independence } 8\end{array}$ & $42+$ & 0 & $\begin{array}{c}\text { Sensitivity } 8 \\
\text { Tough-Mindedness } 3\end{array}$ & MD, NPD & + \\
\hline 3 & $53+$ & 5 & Self-reliance 8 & & & & $\mathrm{ADm}$ & ? \\
\hline 4 & $69+$ & 14 & $\begin{array}{c}\text { Sensitivity } 8 \\
\text { Vigilance } 8 \\
\text { Self-reliance } 10 \\
\text { Perfectionism } 10 \\
\text { Anxiety } 10 \\
\text { Self-control } 9.5\end{array}$ & & & & $\begin{array}{l}\text { NPD } \\
\text { HD }\end{array}$ & ? \\
\hline 5 & $35+$ & 5 & $\begin{array}{c}\text { Warmth } 8 \\
\text { Reasoning } 8 \\
\text { Sensitivity } 8 \\
\text { Abstractedness } 8 \\
\text { Apprehension } 8 \\
\text { Extraversion } 8\end{array}$ & & & & $\begin{array}{l}\mathrm{DD} \\
\mathrm{ADm}\end{array}$ & ? \\
\hline 6 & $81+$ & 23 & $\begin{array}{c}\text { Sensitivity } 8 \\
\text { Abstractedness } 8 \\
\text { Apprehension } 8 \\
\text { Openness to change } 10 \\
\text { Tension } 8\end{array}$ & $71+$ & 21 & $\begin{array}{c}\text { Reasoning } 8 \\
\text { Emotional Stability } 1 \\
\text { Sensitivity } 9 \\
\text { Abstractedness } 10 \\
\text { Apprehension } 8 \\
\text { Openness to change } 10 \\
\text { Tough-Mindedness } 1 \\
\text { Independence } 1\end{array}$ & $\begin{array}{c}\text { MD, } \\
\text { NPD Grief }\end{array}$ & $+?$ \\
\hline 7 & $50+$ & 4 & $\begin{array}{c}\text { Sensitivity } 8 \\
\text { Apprehension } 8\end{array}$ & $65+$ & 1 & $\begin{array}{l}\text { Self-reliance } 10 \\
\text { Tension } 8 \\
\text { Infrequency } 9\end{array}$ & AAg & ? \\
\hline 8 & $54+$ & 16 & $\begin{array}{c}\text { Sensitivity } 8 \\
\text { Apprehension } 8 \\
\text { Self-reliance } 8 \\
\text { Tension } 8 \\
\text { Impression Management } 8 \\
\text { Anxiety } 8 \\
\text { Self control } 9\end{array}$ & $38+$ & 10 & $\begin{array}{c}\text { Warmth } 8 \\
\text { Sensitivity } 9 \\
\text { Apprehension } 8 \\
\text { Self-reliance } 8 \\
\text { Tension } 9 \\
\text { Impression Management } 8 \\
\text { Anxiety } 8 \\
\text { Self control } 8\end{array}$ & $\begin{array}{l}\text { MD } \\
\text { OCPD }\end{array}$ & + \\
\hline
\end{tabular}

"SMBM: Total raw scores and testing positive (+) or not. ${ }^{* *} 16-\mathrm{PF}$ : Scores adjusted for deviations below 3.5 or above $7.5 .{ }^{* * *}$ Clinical diagnoses assessed at the end of the program; NPD: Narcissistic personality disorder; MD: Major depression; ADm: Adjustment disorder with mixed symptoms; HD: Hypochondria disorder; DD: Dysthymia Disorder; UPD: Undiagnosed Personality Disorder; Grief: Coinciding with the end of the APEP, suffered a major grieving process; AAg: Anxiety with agoraphobia; OCPD: Obsessive-compulsive personality disorder.

cannot be easily discarded in favour of psychosocial concepts or notions that are much less delimited and useful. For instance, it is difficult to work as a primary care professional while suffering from major depression. However, despite the difficulties, a sufficiently sensitive, self-critical and perfectionist personality will "hang on" in this work for years... to the point of exhaustion. In the opposite direction, a narcissistic personality that must withstand complaints, demands, and disturbances related to dozens of interactions every day will find it difficult to 
tolerate this work over the long term. In other cases, agoraphobia or hypochondria or somatisation disorders represent almost a contraindication for this type of healthcare activity. On the other hand, the repeated appearance of adjustment disorder is perfectly coherent, because from the psychopathology perspective the burnout syndrome could possibly be considered an adjustment disorder, as has been argued elsewhere [24,35-37].

All of these psychopathology syndromes could also be obscuring serious (dependent, narcissistic, borderline, paranoid or schizoid) personality disorders and even severe mental disorders (psychosis, addictions, bipolar disorder). Therefore, instead of burnout or professional exhaustion syndrome, it might be preferable to talk about personal discomfort consisting of symptoms such as tiredness, anger, irritability, lack of interest in work, relationship problems, etc., that the person in question or those around him or her, or some consulting health professional, attributes to the work environment, independently of whether this aetiology can be proven or not.

Within this perspective, the workplace can carry a lot of weight as either a major risk factor for disequilibrium or a resilience (or containment) factor [35,37]. We must always pay attention to the containment and therapeutic value of work and workplace relationships [36]. On the other hand, some working conditions contribute to psychopathology, constituting a risk factor for mental health [23,24,34-37]. What's more, from our perspective, this is among the most relevant risk factors groups. For example, working in emergency medicine or intensive monitoring, intensive care or neonatal units for years, without the persistent support of ongoing professional training and psychological support, is a known risk factor for physical and mental health $[10,11,18,22,23]$. We also know this about teachers and the fire and police forces [12-14]. Why, then, do we not talk about psychopathologic disorders or syndromes aggravated or influenced by working conditions? Perhaps because modern psychiatry tends to discount the influence of work? If true, it would be difficult to strategize and act upon the complex chain of factors that influence the wellbeing or occupational stress of primary care and mental health professionals (Figure 1).

A direct consequence is that undergraduate and postgraduate education and continuous professional training of healthcare personnel must address the psychological -and psychosocial-components of medical practice more thoroughly [34,35,37]. The concept of burnout or professional exhaustion syndrome then becomes notably more complex, as Figure 1 attempts to summarize.

\section{CONCLUSIONS}

1) We need more studies about interventions to prevent burnout using common and well known evaluation

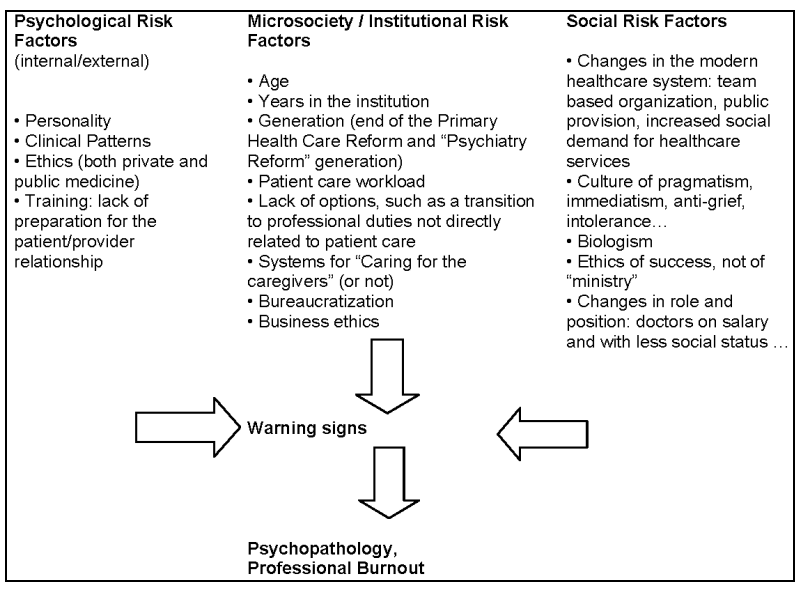

Figure 1. Risk factors for "Psychopathology syndromes influenced by working conditions" or "Burnout syndrome" in primary care and mental health care professionals.

instruments.

2) It is crucial to study and determine the best way to catch the professional's attention and secure their participation in appropriate interventions.

3) The burnout notion may be more useful to describe distress attributed to the job than to delimit the individuals who need professional help for that distress.

Perhaps a more complex perspective that integrates the clinical and psychopathology points of view with the psychosocial is fundamental to understand paradoxes such as those we point out in our APEP preventive intervention program. This perspective still requires much work and it will be worth doing until, paraphrasing Albert Camus in "The plague", when asked "Who taught you all this, doctor?" we will be able to answer, "Suffering, mostly. Both that of others and my own”.

\section{ACKNOWLEDGEMENTS}

To Aitor Antoranz (ICS) for his collaboration in the development of the databases.

\section{REFERENCES}

[1] Freudenberger, H.J. (1974) Staff burnout. Journal of Social Issues, 30, 159-165. doi:10.1111/j.1540-4560.1974.tb00706.X

[2] Maslach, C., and Jackson, S.E. (1986) Maslach burnout inventory. Consulting Psychologist Press, Palo Alto.

[3] Shirom, A. (1989) Burnout in work organizations. In: Cooper, C.L. and Robertson, I., Eds., International Review of Industrial and Organizational Psychology, Wiley, New York, 25-48.

[4] Gil-Monte, P. and Moreno-Jiménez, B. (2007) El síndrome de quemarse por el trabajo (burnout). Grupos profesionales de riesgo. Pirámide, Madrid.

[5] Shirom, A. (2005) Shirom-Mellamed Burnout Measure 
(SMBM). http://www.shirom.org/arie/index.html

[6] Tizón, J.L. (2011) Shirom-mellamed burnout measure. Spanish and Catalan translation of the English original, in collaboration with A. Shirom.

http://www.shirom.org/arie/publications/BurnoutAndVigo rScales/SpanishTranslation\%20SMBM-\%202501\%20201 01\%2014-APEP.pdf

[7] Sobrequés, J., Cebriá, J., Segura, J., Rodríguez, C., García, M. and Juncosa, S. (2002) La satisfacción laboral y el desgaste profesional de los médicos de atención primaria. Atención Primaria, 31, 227-233.

[8] Cathébras, P., Begon, A., Laporte, S., Bois, C. and Truchot, D. (2004) Burn out entre les genéralistes françaises. Presse Médicale, 33, 1569-1574. doi:10.1016/S0755-4982(04)98994-4

[9] Esteva, M., Larraz, C., Soler, J.K. and Yaman, H. (2005) Desgaste profesional en los médicos de familia españoles. Atención Primaria, 35, 108-118. doi:10.1157/13071919

[10] Wu, S., Zhu, W., Wang, A., Wang, M. and Lan, Y. (2007) Relationship between burnout and occupational stress among nurses in China. Journal of Advanced Nursing, 59, 233-239. doi:10.1111/j.1365-2648.2007.04301.x

[11] Imai, H., Nakao, H., Tsuchiya, M., Kuroda, Y. and Katoh, T. (2004) Burnout and work environment of public health nurses involved in mental health care. Occupational and Environmental Medicine, 61, 764-768. doi:10.1136/oem.2003.009134

[12] Olivares, V.E. and Gil-Monte, P. (2007) Prevalencia del síndrome de quemarse por el trabajo (burnout) en trabajadores de servicios en Chile. Informació Psicològica, 91-92, 543-563.

[13] Unda, S., Sandoval, J.I. and Gil-Monte, P. (2007) Prevalencia del síndrome de quemarse por el trabajo (SQT) (burnout) en maestros mexicanos. Informació Psicològica, 91-92, 53-64.

[14] Boudreau, R. and Nakashima, J. (2002) A bibliography of burnout citations, 1990-2002. ASAC, Winnipeg.

[15] Marmot, M.G. (2001) Inequalities in health. New England Journal of Medicine, 345, 134-136. doi:10.1056/NEJM200107123450210

[16] Ahola, K., Gould, R., Virtanen, M., Honkonen, T., Aromaa, A. and Lönnqvist, J. (2009) Occupational burnout as a predictor of disability pension: A population-based cohort study. Occupational and Environmental Medicine, 66, 284-290. doi:10.1136/oem.2008.038935

[17] Generalitat de Catalunya, Departament de Salut (2006) Pla director de salut mental i adiccions (2006-2010). Generalitat de Catalunya, Barcelona.

[18] Frith-Cozens, J. and Payne, R. (1999) Stress in health professionals. John Wiley \& Sons, Chichester.

[19] Stanton, J. and Caan, W. (2003) How many doctors are sick? British Medical Journal Career Focus, 326, 97.

[20] Fundació Galatea (2005) PAIME: Programa de atención integral al Médico enfermo. Fundació Galatea, Barcelona.

[21] Ro, K.E., Gude, T., Tyssen, R. and Aasland, O.G. (2008) Counselling for burnout in Norwegian doctors: One year cohort study. British Medical Journal, 337, 2004. doi:10.1136/bmj.a2004

[22] Rabin, S., Feldman, D. and Caplan, Z. (1999) Stress and intervention strategies in mental health professionals. British Journal of Medical Psychology, 72, 159-169. doi:10.1348/000711299159916

[23] Shapiro, S.L., Shapiro, D.E. and Schwartz, G.E. (2000) Stress management in medical education: A review of the literature. Academic Medicine, 75, 748-759. doi:10.1097/00001888-200007000-00023

[24] Mingote, J.C., Moreno, B. and Gálvez-Herero, M. (2004) Desgaste profesional y salud de los profesionales médicos: Revisión y propuestas de prevención. Medicina Clinica (Barc), 123, 265-270. doi:10.1157/13065203

[25] Brandes, V., Terris, D.D., Fischer, C., Schuessler, M.N., Ottowitz, G., Titscher, G., Fisher, J.E. and Thayer, J.F. (2009) Music programs designed to remedy burnout symptoms show significant effects after five weeks. Annals of the New York Academy of Sciences, 1169, 422-425. doi:10.1111/j.1749-6632.2009.04790.x

[26] Bragard, I., Etienne, A.M., Merckaert, I., Libert, Y. and Razavi, D. (2010) Efficacy of a communication and stress management training on medical residents' self-efficacy, stress to communicate and burnout: A randomized controlled study. Journal of Health Psychology, 15, 10751081. doi:10.1177/1359105310361992

[27] Beckman, H.B., Wendland, M., Mooney, C., Krasner, M.S., Quill, T.E., Suchman, A.L. and Epstein, R.M. (2012) The impact of a program in mindful communication on primary care physicians. Academic Medicine, 87, 815819. doi:10.1097/ACM.0b013e318253d3b2

[28] Goodman, M.J. and Schorling, J.B. (2012) A mindfulness course decreases burnout and improves well-being among healthcare providers. The International Journal of Psychiatry in Medicine, 43, 119-128. doi:10.2190/PM.43.2.b

[29] Deneckere, S., Euwema, M., Lodewijckx, C., Panella, M., Mutsvari, T., Sermeus, W. and Vanhaecht, K. (2013) Better interprofessional teamwork, higher level of organized care, and lower risk of burnout in acute health care teams using care pathways: A cluster randomized controlled trial. Medical Care, 51, 99-107. doi:10.1097/MLR.0b013e3182763312

[30] Awa, W.L., Plaumann, M. and Walter, U. (2010) Burnout prevention: A review of intervention programs. Patient Education and Counseling, 78, 184-190. doi:10.1016/j.pec.2009.04.008

[31] Balch, C.M. and Shanafelt, T. (2010) Combating stress and burnout in surgical practice: A review. Advanced Surgery, 44, 29-47. doi:10.1016/j.yasu.2010.05.018

[32] Arteman, A., Colom, J., Gabilondo, A. and Masachs, E. (2012) La salut i el benestar dels professionals sanitaris en l'entorn laboral. Guia de bones pràctiques per a institucions, equips i professionals. Generalitat de Catalunya, Agència de Salut Pública, Barcelona.

[33] Krasner, M., Epstein, R.M., Beckman, H., Suchman, A.L., Chapman, B., Mooney, C.J. and Quill, T.E. (2009) Association of an educational program in mindful communication with burnout, empathy and attitudes among primary care physicians. Journal of the American Medical Association, 302, 1284-1293. doi:10.1001/jama.2009.1384 
[34] Moreno, B., Gálvez, M., Garrosa, E. and Mingote, J.C. (2006) Nuevos planteamientos en la evolución del burnout. La evaluación específica del desgaste profesional médico. Atención Primaria, 38, 544-549. doi:10.1157/13095925

[35] Tizón, J.L. (2013) Pérdida, pena, duelo. Vivencias, investigación y asistencia. Herder, Barcelona.

[36] Marucco, M., Gil-Monte, P. and Flamenco, E. (2007) Sín- drome de quemarse por el trabajo (burnout) en pediatras de hospitales generales, estudio comparativo de la prevalencia medida con el MBI-HSS y el CESQ. Informació Psicològica, 91-92, 32-43.

[37] Tizón, J.L., Daurella, N. and Cleries X. (2012) Bioingeniería o Medicina? El futuro de la medicina y laformación de los médicos. Red-Ediciones, Barcelona. 